\title{
Analysis of risk factors for depression among patients with chronic low back pain in an orthopaedic clinic of a Nigerian teaching hospital
}

\author{
Njoku Isaac Omoke ${ }^{1}$, Monday Nwite Igwe ${ }^{2}$
}

1. Department of Surgery Ebonyi State University/Federal Teaching Hospital, Abakaliki, Nigeria.

2. Department of Psychological Medicine, Ebonyi State University/Federal Teaching Hospital Abakaliki, Nigeria. Email: mondayigwe@yahoo.com

\begin{abstract}
Background: Depression compounds the burden of chronic low back pain and has implications on the outcome of treatment. Published reports demonstrated a strong association between depression and chronic low back pain. However, there is very scanty data on predisposing factors for depression among these patients.

Objective: To determine the risk factors for depression among patients with chronic low back pain in a Nigerian orthopaedic clinic setting.

Method: Three hundred (300) eligible, consenting and consecutive patients with chronic low back pain in orthopaedic clinic of Federal Teaching Hospital Abakaliki Nigeria were interviewed with Population and Pain Characteristics Questionnaire, General Health Questionnaire (GHQ-12) and Major Depressive Episode of Mini-International Neuropsychiatric Interview (M.I.N.I) over a period of 34 months. Statistically significant factors that emerged from Pearson chi-square test of association were entered into logistic regression analysis to evaluate the risk of each factor when adjusted to other factors.

Depression was observed in 61(20.3\%) of the patients interviewed. Seven factors for depression among these patients emerged from chi square test of association. Logistic regression analysis identified alcohol consumption, severe pain intensity, hypertension co- morbidity and prior traditional healer care as the independent risk factors for depression among the patients.

Conclusion: The independent risk factors for depression identified in this study calls for maintaining a high level of suspicion in the patients with these risk factors to facilitate early recognition of depression, and a high priority accorded to them in the measures aimed at addressing depression for a good therapeutic outcome.

Keywords: Risk factors for depression, chronic low back pain, Nigerian teaching hospital.

DOI: https://dx.doi.org/10.4314/ahs.v19i1.49

Cite as: Omoke NI, MN I. Analysis of risk factors for depression among patients with chronic low back pain in orthopaedic clinic of a Nigerian teaching hospital. Afri Health Sci. 2019;19(1). 1727-1735. bttps:// dx.doi. org/10.4314/ abs. v19i1.49
\end{abstract}

\section{Introduction}

Low back pain is a common health problem globally. The transition of low back pain to chronicity has implications in its morbidity and cost of treatment ${ }^{1}$. In published re-

\section{Corresponding author:}

Njoku Isaac Omoke, Department of Surgery

Ebonyi State University/Federal Teaching Hospital

Abakaliki PMB 102

Post Code 400081

Ebonyi State, Nigeria

Telephone: +2348035714099

Email: zicopino@yahoo.com ports, the proportion of low back pain that transits to chronicity ranges from $8.7-39 \% 0^{2-3}$. In USA, a recently published report indicated a rising prevalence of chronic low back pain ${ }^{4}$. In Nigeria, chronic low back pain accounted for $60-73 \%$ of low back pain seen in tertiary health care settings $\mathrm{s}^{5-6}$. The disability and morbidity associated with chronic low back pain is an enormous burden when aggravated by concomitant depression ${ }^{7}$.

The strong association between depression and chronic low back pain was well demonstrated in previous published reports ${ }^{8-11}$. This correlation has been attributed to the common pathway and neurotransmitters in central nervous system for pain and depression ${ }^{11}$. In a Canadian population, depression is three to four times more in pa-

(C) 2019 Omoke et al. Licensee African Health Sciences. This is an Open Access article distributed under the terms of the Creative commons Attribution License (https://creativecommons.org/licenses/BY/4.0), which permits unrestricted use, distribution, and reproduction in any medium, provided the original work is properly cited. 
tients with chronic back pain than in general population ${ }^{8}$. Depression has implication in the outcome of measures aimed at eradicating low back pain. Thus, poor outcome is likely when treatment is focused on pain without addressing concomitant depression ${ }^{11,12,13}$. Unfortunately, missed-diagnosis of depression in chronic low back pain is common because the attending physician is often times focused on finding the physical cause of pain and patients often do not realize that depression is part of their problem $^{10}$. Therefore, it is imperative that the attending physician is well armed with clinical skills that aid early recognition of depression among patients with chronic low back pain.

In recent published reports, the prevalence of depression among patients with chronic low back pain ranges from 20 to $64.8 \% 12,14,15,16$. The findings in these published reports ${ }^{12,14,15,16}$ also indicate that depression is not present in every patient with chronic low back pain. This implies that there are risk factors that predispose patients with chronic low back pain to depression. A detailed knowledge of these risk factors for depression among patients with chronic low back pain in a setting can facilitate early recognition and treatment of depression to achieve optimum outcome in the management of pain.

Therefore, the aim of this study was to determine the risk factors of depression among patients with chronic low back pain in a teaching hospital orthopaedic clinic setting of a developing country.

\section{Patients and methods}

Study setting and design: This study was a cross-sectional questionnaire-based survey carried out among patient with chronic low back pain in the orthopaedic clinic of Federal Teaching Hospital Abakaliki, Ebonyi State Nigeria. The hospital came into existence in the year 2011 after a successful merger of the Ebonyi State University Teaching Hospital and Federal Medical Centre Abakaliki by the Federal Government of Nigeria.

\section{Ethical approval}

The approval for this study was obtained from the Ethics and Research Committee of Federal Teaching Hospital Abakaliki, Ebonyi State Nigeria. A written informed consent was obtained from the patients and /or next of kin before the study instruments were administered.

\section{Inclusion criteria}

All patients with chronic low back pain ( $>12$ weeks du- ration) aged 18 years and above who presented in the orthopedic clinic and gave informed consent to participate in the study.

\section{Exclusion criteria:}

Patients that have established co-morbid mental disorder, cognitive impairment and those who objected to giving informed consent were excluded from the study.

\section{Instruments for the study}

\section{The Population and Pain Characteristics Ques-} tionnaire. This questionnaire was designed to provide information about the patient's age, gender, marital status, level of educational, occupation and employment status, social habits (alcohol consumption and smoking), dependent/independent livelihood status, hobbies, medical co-morbidities and traditional healer care prior to presentation. The information provided about characteristics of low back pain was mode of onset of pain, duration of pain, severity of pain, periodicity of pain and perceived cause of pain. The severity of pain was assessed using the visual analog scale (VAS) where 0 represented no pain and $100(\mathrm{~mm})$ represented the severest type of pain. The dependent livelihood status group in this study is patients (irrespective of employment status) that are wholly or partly dependent on family, relations, friends and well-wishers for sustenance. In this study, traditional healers are practitioners of traditional medicine.

\section{The General Health Questionnaire (GHQ-12).-} The twelve-item General Health Questionnaire was developed by Goldberg and Williams in $1988^{17}$. It was intended for use as a screening tool for non-specific psychiatric morbidity, focusing essentially on the inability of a patient to carry out normal functions and the appearance of new and distressing experiences. The GHQ-12 has been widely validated and found to be reliable ${ }^{18}$. Scoring each of the 12 items is by Likert scale of 0 to 3 , giving a score range of 0 to 36. A score of 16 and above indicates presence of psychological distress.

\section{Major Depressive Episode (MDE) of Mini-In-} ternational Neuropsychiatric Interview. The MiniInternational Neuropsychiatric Interview (M.I.N.I) is a short structured diagnostic interview developed jointly by a group of psychiatrists and clinicians for DSM-IV and ICD-10 psychiatric disorders. It was designed to meet the need for a short but accurate structured psychiatric interview for multicenter clinical trials and epidemiology 
studies ${ }^{19}$. This instrument has been widely used by health professionals and has been translated into many languag$\mathrm{es}^{20}$. There are many modules for diagnostic categories but only the MDE module was used. The MDE module of M.I.N.I is grouped as A module and has six sectionsA1 to A6. In this study, questions A1 to A3 were used since the study assesses MDE, (current). For a diagnosis of MDE (current) to be made, there has to be 5 or more yes codes in questions A1 to A3.

Procedure: Three hundred consecutive and consenting patients who meet the inclusion criteria were recruited into the study from January 2014 and October 2017 in the orthopedic clinic. They were interviewed using the Population and Pain Characteristic Questionnaire; the GHQ-12 and MDE module of M.I.N.I. Participants who were not literate were interviewed with the translated Igbo language versions of the instruments. The
GHQ-12 questionnaire was used as a screening test for psychological distress. Participants that had GHQ-12 score of 16 and above underwent further interview using MDE module of M.I.N.I. A score of five (5) and above in MDE module confirmed depression in a psychologically distressed participant. For statistical analysis, patient were classified into three age groups (18-39, 40-65 and $>65$ years), male and female, marital status (single, married and widowhood), formal educational status (None, primary, secondary, and tertiary) and employment status (student/apprentice, employed, unemployed and retired). The patients were also classified into 3 groups based on pain intensity rating on VAS, mild $(1-39 \mathrm{~mm})$, moderate $(40-69 \mathrm{~mm})$ and severe $(70-100 \mathrm{~mm})$. In this study, the employed includes the self -employed patients (farmers, artisans, traders etc) government and private sector employees. The patients were further classified for analysis as shown in Table 1.

\section{Table 1: Potential risk factors for depression in chronic low back pain and classification of patients for statistical analysis}

$* \mathbf{T H}=$ Traditional Healer

\begin{tabular}{|c|c|c|c|}
\hline Probable risk factor & Bas is of grouping & Group 1 & Group 2 \\
\hline Livelihood status & financial/economic capability & dependent & independent \\
\hline Alcohol & alcoholic drinks consumption & yes & no \\
\hline Smoking & tobacco cigarette smoking & yes & no \\
\hline Type of hobby & sedentary / non-sedentary & sedentary & non- sedentary \\
\hline Prior $\mathrm{TH}^{*}$ care & $\mathrm{TH}^{*}$ care prior to hospital vis it & yes & no \\
\hline Onset of pain & insidious / sudden & insidious & sudden \\
\hline Periodicity of pain & recurrent / persistent & recurrent & persistent \\
\hline Duration of pain & duration of pain prior to presentation & $>3$ to 12 months & $>12$ months \\
\hline Notion about the pain & patient opinion about cause of pain & yes & no \\
\hline \multirow[t]{5}{*}{ Co-morbidities } & presence of co-morbidities such as: & & \\
\hline & Hypertension & yes & no \\
\hline & Diabetes mellitus & yes & no \\
\hline & Peptic ulcer dis ease & yes & no \\
\hline & Osteoarthritis & yes & no \\
\hline
\end{tabular}

\section{Statistical analysis}

Data analysis was carried out using Statistical Package for Social sciences SPSS version 16 (SPSS Inc; Chicago, Illinois., USA). Bivariate analysis was carried out and statistically significant factors $(\mathrm{p}<0.05)$ that emerged from
Pearson chi-square test of association were entered into a stepwise logistic regression model for multivariate analysis to evaluate the risk of each factor when adjusted to other factors. In the logistic regression analysis, $\mathrm{p}$ value $<$ 0.05 was considered significant. 


\section{Results}

There were 307 patients with chronic low back pain, $300(97.7 \%)$ met the inclusion criteria. The six $(2 \%)$ that had established co-morbid mental disorder and one
$(0.3 \%)$ that declined participation in the study were excluded. There was depression in 61(20.3\%) of the $300 \mathrm{pa}-$ tients with chronic low back pain studied. The risk factors for depression among the patients were identified in the bivariate analysis as shown in Table 2, 3, 4 and 5 .

Table 2: Depression in chronic low back pain by socio-demographic characteristics of the population

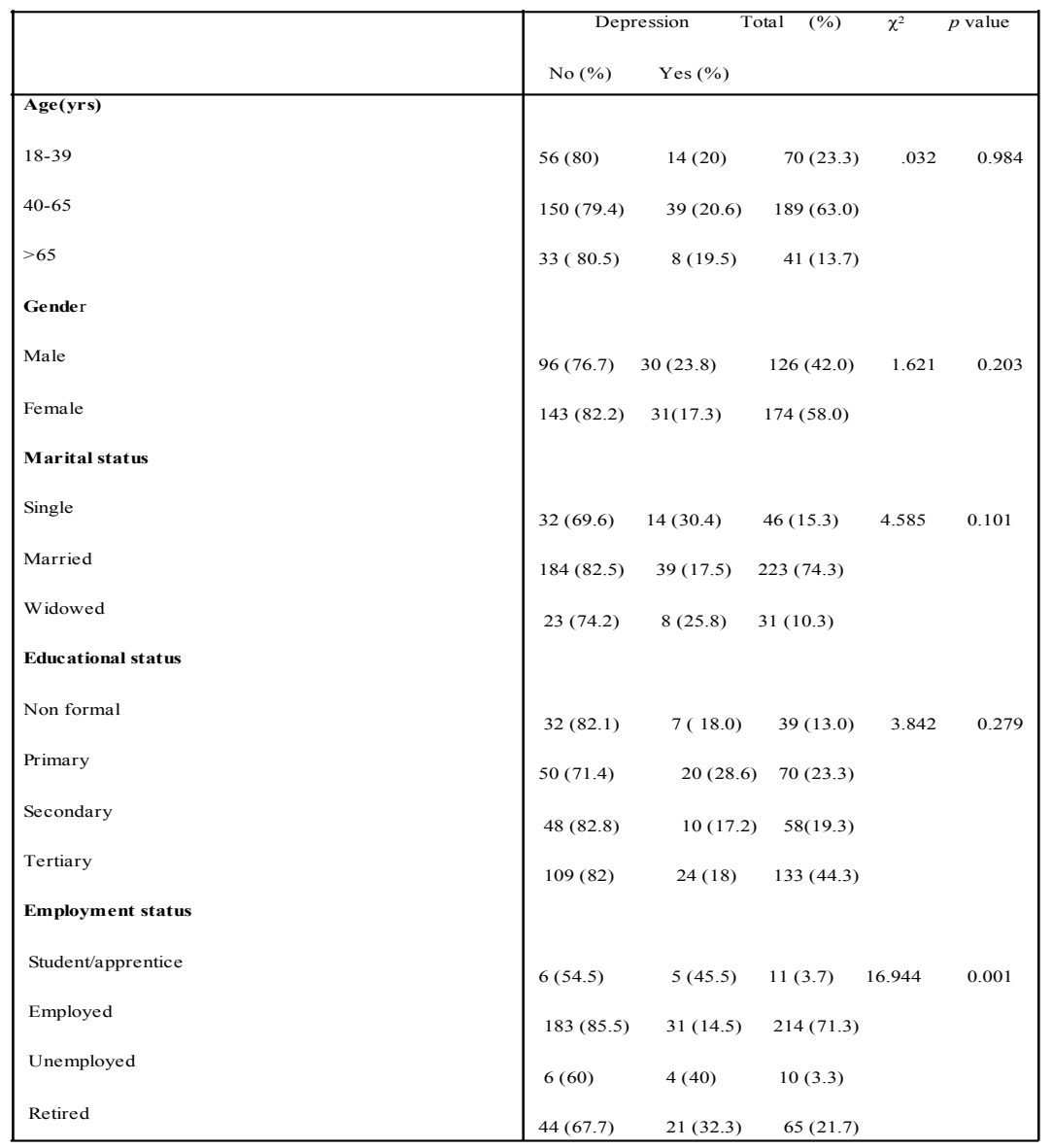

Table 3: Depression in chronic low back pain by Life style related factors

\begin{tabular}{|l|ccccc|}
\hline & \multicolumn{2}{|c}{ Depression } & Total (\%) & $\chi^{2}$ & $p$ value \\
\hline Type of hobby & No (\%) & Yes (\%) & & & \\
$\begin{array}{l}\text { Sedentary } \\
\text { Non-sedentary }\end{array}$ & $178(78.8)$ & $48(21.2)$ & $226(75.3)$ & 0.464 & 0.496 \\
$\begin{array}{l}\text { Alcohol } \\
\text { Yes }\end{array}$ & $61(82.4)$ & $13(17.6)$ & $74(24.7)$ & & \\
No & $49(63.6)$ & $28(36.4)$ & $77(25.7)$ & 16.433 & 0.000 \\
$\begin{array}{l}\text { Smoking } \\
\text { Yes }\end{array}$ & $190(85.2)$ & $33(14.3)$ & $223(74.3)$ & & \\
No & $8(66.7)$ & $4(33.3)$ & $12(4.0)$ & 1.304 & 0.253 \\
$\begin{array}{l}\text { Prior TH care } \\
\text { Yes }\end{array}$ & $231(80.2)$ & $57(19.8)$ & $288(96)$ & & \\
No & $25(52.1)$ & $23(47.9)$ & $48(16.0)$ & 26.839 & 0.000 \\
Livelihood status & $214(84.9)$ & $38(15.1)$ & $252(84.0)$ & & \\
$\begin{array}{l}\text { Dependent } \\
\text { Independent }\end{array}$ & $66(68.8)$ & $30(31.2)$ & $96(32)$ & 10.386 & 0.001 \\
\hline
\end{tabular}


Table 4: Depression among patients with chronic low back pain by characteristics of pain

\begin{tabular}{|c|c|c|c|c|c|}
\hline & \multicolumn{2}{|c|}{ Depression } & \multirow[t]{2}{*}{ Total (\%) } & \multirow[t]{2}{*}{$\chi^{2}$} & \multirow[t]{2}{*}{$p$ value } \\
\hline & No $(\%)$ & Yes $(\%)$ & & & \\
\hline \multicolumn{6}{|c|}{ Pain intensity } \\
\hline Mild & $30(93.8)$ & $2(6.2)$ & $32(10.7)$ & 18.811 & 0.000 \\
\hline Moderate & $110(88.0)$ & $15(12.0)$ & $125(41.7)$ & & \\
\hline Severe & $99(69.2)$ & $44(30.8)$ & $143(47.7)$ & & \\
\hline \multicolumn{6}{|c|}{ Onset of pain } \\
\hline Insidious & $156(77.6)$ & $45(22.4)$ & $201(67.0)$ & 1.587 & 0.208 \\
\hline Sudden & $83(83.8)$ & $16(16.2)$ & $99(33)$ & & \\
\hline \multicolumn{6}{|c|}{ Periodicity of pain } \\
\hline Recurrent & $169(84.1)$ & $32(15.9)$ & $201(67)$ & 7.322 & 0.007 \\
\hline Persistent & $70(70.7)$ & $29(29.3)$ & $99(33.0)$ & & \\
\hline \multicolumn{6}{|c|}{ Duration of pain(months) } \\
\hline$>3$ to 12 & $70(76.9)$ & $21(23.1)$ & $91(30.3)$ & 0.607 & 0.436 \\
\hline$>12$ & $169(80.9)$ & $40(19.1)$ & $209(69.7)$ & & \\
\hline \multicolumn{6}{|c|}{ Notion about the pain } \\
\hline Yes & $148(82.7)$ & $31(17.3)$ & $179(59.7)$ & 2.490 & 0.115 \\
\hline No & $91(75.2)$ & $30(24.8)$ & $121(40.3)$ & & \\
\hline
\end{tabular}

Table 5: Depression in chronic low back pain by co-morbidities

\begin{tabular}{|c|c|c|c|c|c|}
\hline & \multicolumn{2}{|c|}{ Depression } & \multirow[t]{2}{*}{ Total(\%) } & \multirow[t]{2}{*}{$\chi^{2}$} & \multirow{2}{*}{$p$ value } \\
\hline & No $(\%)$ & Yes $(\%)$ & & & \\
\hline Hypertension & & & & & \\
\hline Yes & $59(67.8)$ & $28(32.2)$ & $87(29.0)$ & 10.623 & 0.001 \\
\hline No & $180(84.5)$ & $33(15.5)$ & $213(71.0)$ & & \\
\hline Diabetes Mellitus & & & & & \\
\hline Yes & $15(83.3)$ & $3(16.7)$ & $18(6)$ & 0.159 & 0.690 \\
\hline No & $224(79.4)$ & $58(20.6)$ & $282(94)$ & & \\
\hline Peptic ulcer disease & & & & & \\
\hline Yes & $36(78.3)$ & $10(21.7)$ & $46(15.3)$ & 0.066 & 0.797 \\
\hline No & $203(79.9)$ & $51(20.1)$ & $254(84.7)$ & & \\
\hline Osteoarthritis & & & & & \\
\hline Yes & 49 (76.6) & $15(23.4)$ & $64(21.3)$ & 0.484 & 0.487 \\
\hline No & $190(80.5)$ & $46(19.5)$ & $236(78.7)$ & & \\
\hline
\end{tabular}

The incidence of depression in chronic low back pain was related to employment status $(\mathrm{p}<0.001)$, the highest rate of depression was among students/apprentices and the least among the employed as shown in Table 2. The life style related factors that correlated with high incidence of depression in chronic low back pain were alcohol consumption $(\mathrm{p}<0.001)$, prior traditional healer care $(\mathrm{p}<0.001)$, and dependent livelihood status $(\mathrm{p}<0.001)$ as shown in Table 3. In Table 4, depression was significantly $(p<0.001)$ related to pain intensity, and its rate increased in a linear form with greater pain intensity that from $6.2 \%$ in mild pain it doubled and quintupled in moderate and severe pain intensity respectively. The periodicity of pain was also related to the rate of depression, a higher rate 
in persistent than in recurrent chronic low back pain $(\mathrm{p}<$ 0.007). Hypertension co- morbidity correlated $(p<0.001)$ with high incidence of depression in chronic low back pain as shown in Table 5.

The result of multivariate analysis to determine the risk of each factor when adjusted to other factors was summarized in logistic regression model as shown in Table 6. In the model, alcohol consumption $(\mathrm{p}<0.001)$, hypertension co- morbidity $(\mathrm{p}<0.001)$, prior traditional healer care $(p=0.004)$ and pain intensity $(p<0.015)$ were identified as the independent risk factors for depression. There were three levels of pain intensity and mild pain was considered as a reference category: the first contrast that compared those with mild pain with those with moderate pain was not significant $(p<0.356)$ whereas the second contrast that compared those with mild pain with those with severe pain was significant $(\mathrm{p}<0.039)$. The patients with severe pain were 5.3 times more likely to have depression than those with mild pain. The risk of depression was not significantly different between mild and moderate levels of pain intensity.

The logistic regression model was found to be an appropriate model (Chi square 68.021; $\mathrm{df}=10$; $\mathrm{p}$ value $<$ $0.001)$ and Hosmer Lemeshow goodness of fit test ( $p=$ 0.3) revealed no significant departure from a good fit.

Table 6: Multivariate analysis of risk factors for depression in chronic low back pain: summary of logistic regression model

\begin{tabular}{|c|c|c|c|c|c|c|c|c|}
\hline \multirow[t]{2}{*}{ Risk factors } & \multirow[t]{2}{*}{$\mathrm{B}$} & \multirow[t]{2}{*}{ SE } & \multirow[t]{2}{*}{ Wald } & \multirow[t]{2}{*}{$\mathrm{df}$} & \multirow[t]{2}{*}{ Sig (p value) } & \multirow[t]{2}{*}{$\operatorname{Exp}(B)$} & \multicolumn{2}{|c|}{$95 \% \mathrm{CI}$ interval } \\
\hline & & & & & & & Lower & Upper \\
\hline Livelihood status & .552 & .416 & 1.761 & 1 & 0.185 & 1.736 & $0.769-$ & 3.922 \\
\hline Alcohol & 1.283 & .358 & 12.830 & 1 & 0.000 & 3.606 & $1.787-$ & 7.274 \\
\hline Hypertension & 1.252 & .375 & 11.115 & 1 & 0.001 & 3.499 & $1.678-$ & 7.797 \\
\hline Periodicity of pain & .310 & .346 & 0.910 & 1 & 0.370 & 0.734 & $0.373-$ & 1.444 \\
\hline Prior TH care & 1.163 & .402 & 8.379 & 1 & 0.004 & 3.200 & $1.456-$ & 7.035 \\
\hline Pain intensity & & & 0.853 & 2 & 0.015 & & & \\
\hline moderate & 0.753 & .821 & 0.853 & 1 & 0.356 & 2.134 & $0.427-$ & 10.661 \\
\hline Severe & 1.669 & .807 & 4.282 & 1 & 0.039 & 5.307 & $1.092-$ & 25.786 \\
\hline Employment status & & & 1.655 & 3 & 0.647 & & & \\
\hline student/apprentice & .720 & .813 & .785 & 1 & 0.376 & 2.055 & $0.418-$ & - $\quad 10.113$ \\
\hline employed & -.228 & .452 & .255 & 1 & 0.614 & 0.796 & $0.328-$ & 1.931 \\
\hline unemployed & .418 & .809 & .267 & 1 & 0.605 & 1.519 & $0.328-$ & 7.417 \\
\hline Constant & -3.612 & .978 & 13.628 & 1 & 0.801 & 0.27 & & \\
\hline
\end{tabular}

\section{Discussion}

The incidence of depression among chronic low back pain patients in this study is within the worldwide range $12,14,15,16$. Although a strong association between depression and chronic low back pain has been well demonstrated in previous published reports ${ }^{8-11}$, data on the risk factors that predisposes a patient with chronic low back pain to concomitant depression is very scanty ${ }^{8}$. Currie and Wang reported that the rate of major depression increased in a linear fashion with greater pain severity ${ }^{8}$; this is similar to direct linear correlation between rate of depression and pain intensity in this study. However, when adjusted to other factors, pain intensity was an independent risk factor in this study: patients with severe pain were 5.3 times more likely to have depression than those with mild pain whereas the risk of depression was not significantly different between mild and moderate pain intensity though the rate of depression in the later was twice in the former. 
This implies that severe pain is significantly the important level of pain intensity that predisposes patient with chronic low back pain to depression. This also indicates that either the presence of concomitant depression increases the severity of pain as described by the patient or despair, a consequence of severe chronic low back pain.

In this study, alcohol use is a modifiable risk factor for depression among chronic low back pain patients. Previous published report also indicates that alcohol use correlates positively with depressive symptomatology ${ }^{21}$. Self-medication with alcohol as a potentially adaptive method of coping with musculoskeletal pain and the associated stress is common among the patients ${ }^{22}$. Graham et al demonstrated that the main factor linking depression with alcohol consumption is consuming larger amounts per occasion ${ }^{23}$. All these findings suggest that among the chronic low back pain population, alcohol drinkers compared to abstainers are more likely to use alcohol to the quantity per occasion that is significantly associated with depression. This perhaps explains the identification of alcohol consumption, in this study, as one of the independent risk factors for depression among these patients with chronic low back pain. Therefore, in the management of these patients, this information about alcohol consumption as a potential and independent risk factor for depression that compounds the burden of chronic low back pain should be passed on to them.

Hypertension was an independent risk factor for depression in patients with chronic low back pain in this study. This is in keeping with the link between chronic pain, hypertension and depression in published reports ${ }^{24-25}$. Bruehi et al demonstrated that chronic pain such as chronic low back pain is associated with increased risk of hypertension and chronic pain intensity was a significant predictor of clinical hypertensive status ${ }^{24}$. In a systematic review, Scalco et al concluded that there is considerable documented evidence, indicating that sympathetic nervous system dysfunction and genetic factors are the underlying mechanisms in the link between depression and hypertension ${ }^{25}$. Therefore, in clinical evaluation of chronic low back pain positive history of hypertension co- morbidity is important and calls for further assessment to rule out concomitant depression.
In the setting of this study, traditional healers are easily accessible, and strong belief in them as care givers in musculoskeletal painful disorders and trauma is common among the general population ${ }^{26}$. Thus, hopelessness and despair as result of failure of traditional medicine to eradicate low back pain is more likely among the ardent believers that first sought care from the practitioners prior to hospital presentation. This perhaps explains the prior care of low back pain by traditional healers as an independent risk factor for depression observed in this study.

Based on established strong correlation between depression and chronic low back pain as well the implications of depression on the outcome of the treatment, researchers have recommended screening for depression in every patient with chronic low back pain as an essential aspect of care $^{7,13}$. However, screening for depression in every patient with chronic low back pain could be quite challenging in an environment with inadequate number of healthcare personnel and low literacy level, as often the case in developing countries. These independent risk factors for depression, severe pain intensity, prior care by traditional healer and positive history of alcohol consumption and hypertension co- morbidity can all be sought from every patient with chronic low back pain during clinical evaluation and a high level of suspicion maintained as well as priority given to screening for depression when these factors are present.

\section{Limitations}

The limitations of this study include its being a cross sectional hospital and single centre based one. The data obtained may not be a representation of the entire chronic low back pain population. Despite these limitations, the findings from this study are quite strong and can serve as a baseline data for comparison in future studies.

\section{Conclusion}

There are several risk factors for depression among patients with chronic low back pain. The independent risk factors identified in this study calls for maintaining a high level of suspicion in the patients with these risk factors to facilitate early recognition of depression, and a high priority accorded to them in the measures aimed at addressing concomitant depression for a good therapeutic outcome of chronic low back pain management. 


\section{Financial support}

None.

\section{Acknowledgement}

We thank Mr. Paul Ndidi Nkadi, Rev Sr. Rosemary Uwakwe HHCJ and Resident Doctors in Department of Surgery who were very helpful in the process of data collection.

\section{Conflict of interest}

None.

\section{References}

1. Anderson GBJ. Epidemiological features of chronic low back pain. Lancet. 1999; 354:581-585. PubMed.

2. Coste J, Delecoeuillerie G, Cohen de Lara A, Le Parc JM, P Gurcay E, Bal A, Eksioglu E, Hasturk AE et al. Acute low back pain clinical course and prognostic factors. Disabil Rehabil.2009; 31(10): 840-845.

3. Thomas E, Silman AJ, Croft PR, Papageorgiou AC, Jayson MI, Macfarlane GJ. Predicting

3. Jones GT, Johnson RE, Wiles NJ, Chaddock C et al. Predicting persistent disabling low back pain in general practice: prospective cohort study. Br J Gen Pract. 2006; 56(526):334-341.

4. Freburger JK, Holmes GM, Agans RP, Jackman AM, Darter JD, Wallace AS et al. The rising prevalence of chronic low back pain. Arch Intern Med. 2009; 169(3): 251258.

5. Omoke NI, Amaragbulam PI. Low back pain as seen in orthopaedic clinics of a Nigerian Teaching Hospital. Niger J Clin Pract. 2016; 19: 212-217. PubMed.

6. Eyichukwu GO, Ogugua PC. Epidemiology of low back pain in Enugu, Nigeria. Niger J Orthop Trauma. 2012; 11:28-35.

7. Tsuji T, Matsudaira K, Sato H, Vietri J. The impact of depression among chronic low back pain patients in Japan. BMC Musculoskeletal Disorder. 2016; 17:447 p 1-9 DOI 10.1186/s 12891-016-13044.

8. Currie SR, Wang J. Chronic back pain and major depression in the general Canadian population. Pain. 2004; 107(1-2):54-60. PubMed.

9. Atkinson HJ, Slater MA, Patterson TL, Grant I. Garfin SR. Prevalence, onset and risk of psychiatrist disorders in men with chronic low back pain: a controlled study. Pain. 1991; 45:111-121. PubMed.
10. Deardorff WW. Depression and chronic back pain. Available from: www.spine-health.com/condition/depression/depression-and-chronic-back-pain Assessed on October 14, 2016.

11. Bair MJ, Robinson RL, Katon W, Kroenke K. Depression and pain co morbidity: a literature review. Arch Intern Med. 2003; 163:2433-2445. PubMed.

12. Love AW. Depression in chronic low back pain patients: diagnostic efficiency of three self -report questionnaires. J Clin Psychol. 1987; 43(1): 84-89. PubMed.

13 Sinikallio S, Aalto T, Airaksinen O, Herno A, Kroger $\mathrm{H}$, Savolainen S, et al Depression is associated with poorer outcome of lumber stenosis surgery. Eur Spine. 2007; 16:905-12. PubMed.

14 Namgwa KJ, Terkura A, William Y, Daniel MD, Cornilius EI. Depression in patients with chronic low back pain: a hospital based study. Niger J. Surg Res. 2016; 17: 1-4. PubMed.

15. Sagheer MA, Khan MF, Sharif S. Association between chronic low back pain anxiety and depression in patients at a tertiary care centre. J Pak Med Assoc. 2013; 63: 688-690. PubMed.

16. Pande KC. Psychological disturbances in Indian low back pain population. Indian J Orthop. 2004; 38:175-177. PubMed.

17. Goldberg D, Williams P. A user's guide to the General Health Questionnaire. 1988; Slough: NFER-Nelson.

18. Hankins M. The reliability of the twelve-item general health questionnaire (GHQ-12) under realistic assumptions. BMC Public Health. 2008; 8:355.

19. Sheehan DV, Lecrubier Y, Sheehan K.H, Amorim P, Janavs J, Weiller E et al. The Mini-International Neuropsychiatric Interview (M.I.N.I.): the development and validation of a structured diagnostic psychiatric interview for DSM-IV and ICD-10. J Clin Psychiatry. 1998; 59 Suppl 20: 22-33.

20. Otsubo T, Tanaka K, Koda R, Shinoda J, Sano N, Tanaka $S$ et al. Reliability and validity of Japanese version of the Mini-International Neuropsychiatric Interview. Psychiatry Clin Neurosci. 2005; 59 (5): 517-526.

21. Hartka E, Johnstone B, Leino EV, Motoyoshi M, Temple MT, Fillmore KM et al. A meta-analysis of depressive symptomatology and alcohol consumption overtime. $\mathrm{Br} \mathrm{J}$ Addict. 1991; 86(10):1283-1298.

22. Riely III JL, King C. Self report of alcohol use for pain in a multi-ethnic community sample. Journal of Pain. 2009; 10: 944-952. PubMed. 
23. Graham K, Massak A, Andree D, Rehem J et al. Does the association between alcohol consumption and depression depend on how they are measured? Alcohol Clin Exp Res. 2007; 31(1):78-88.

24. Bruehi S, Chung OY, Jirjis JN, Biridepalli S. Prevalence of clinical hypertension in-patient with chronic pain compared to non pain general medical patients. Clin.J Pain. 2005; 21(2): 147-153. PubMed.
25. Scalco AZ, Scalco MZ, Azul JBS, Lotufo Neto F. Hypertension and depression. Clinics. 2005; 60(3):241-243. PubMed.

26. Iyalomhe GBS, Iyalomhe SI. Health seeking behavior of rural dwellers in Southern Nigeria: implications for health care professional. Int J Trop Dis Health. 2012; 2 (2):62 -71. PubMed. 